\title{
Accuracy of clinical-functional tools to identify risk of falls among community-dwelling older adults
}

\author{
Acurácia de ferramentas clínico-funcionais para \\ identificar risco de quedas em idosos comunitários
}

Precisión de herramientas clinico-funcionales para
identificar riesgo de caídas em ancianos comunitários

Raphaela Xavier Sampaio $₫$, Amanda Maria Santos Abreu $₫$,
Cristiane Almeida Nagata $₫$, Patrícia Azevedo Garcia $\circledast^{*}$

Universidade de Brasília (UnB), Brasília, DF, Brazil

Abstract

Introduction: The identification of older adults who present greater chances of falling is the first step in the prevention of falls. Clinical instruments have been shown to be able to differentiate fallers from nonfallers, but their predictive validity remains controversial. Objective: To investigate the accuracy of the Short Physical Performance Battery (SPPB) and Quick Screen Clinical Fall Risk Assessment (QuickScreen) instruments to identify risk of falls in community-dwelling older adults. Method: This is a prospective methodological study with 81 older adults ( $\geq 60$ years), assessed at baseline by SPPB and QuickScreen and monitored after one year to identify the occurrence of falls. Sensitivity, specificity, positive predictive

* RXS: BS, e-mail: rapha.sampabm@gmail.com AMSA: BS, e-mail: amandahabreu@hotmail.com CAN: MS, e-mail: cris_gyn@hotmail.com

PAG: PhD, e-mail: patriciaagarcia@hotmail.com 
value (PPV), negative predictive value (NPV) and area under the ROC curve (AUC) were calculated. Results: $28.4 \%$ of the sample reported falls. QuickScreen presented $52.2 \%$ sensitivity, $74.1 \%$ specificity, $44.4 \%$ PPV, $79.6 \%$ NPV and 0.656 AUC. The AUC for SPPB was not significant ( $p=0.087)$. Conclusion: QuickScreen presented poor accuracy when predicting falls and SPPB was unable to identify community-dwelling older adults at risk of falls. The QuickScreen instrument stood out for its high potential to identify true negatives.

Keywords: Older Adults. Accidental Falls. Risk Factors. Risk Assessment. Sensitivity and Specificity.

\section{Resumo}

Introdução: A identificação dos idosos com maior chance de cair caracteriza o primeiro passo para a prevenção de quedas. Ferramentas clínicas têm se mostrado capazes de diferenciar idosos caidores de não caidores, porém suas validades preditivas permanecem controversas. Objetivo: Investigar a acurácia das ferramentas Short Physical Performance Battery (SPPB) e Quick Screen Clinical Fall Risk Assessment (QuickScreen) para identificação de risco de quedas em idosos comunitários. Método: Estudo metodológico prospectivo com 81 idosos ( $\geq 60$ anos), avaliados na linha de base por meio da SPPB e da QuickScreen e monitorados após 1 ano para identificação de ocorrência de quedas. Calculou-se a sensibilidade, a especificidade, o valor preditivo positivo (VPP), o valor preditivo negativo (VPN) e a área abaixo da curva ROC (AUC). Resultados: $28,4 \%$ dos idosos relataram quedas. $O$ QuickScreen apresentou sensibilidade de 52,2\%, especificidade de 74,1\%, VPP de 44,4\%, VPN de 79,6\% e AUC de 0,656. A AUC do SPPB não foi significativa ( $p=0,087)$. Conclusão: A ferramenta QuickScreen apresentou fraca acurácia para prever quedas e o SPPB mostrou-se incapaz de identificar idosos comunitários em risco de cair. A ferramenta QuickScreen destacou-se por seu alto potencial de identificar verdadeiros negativos.

Palavras-chave: Idoso. Acidentes por Queda. Fatores de Risco. Medição de Risco. Sensibilidade e Especificidade.

\section{Resumen}

Introducción: La identificación de los ancianos con mayor probabilidad de caídas caracteriza el primero paso para la prevención de caídas. Las herramientas clínicas se han mostrado capaces de diferenciar a los ancianos que caen de los que no caen, pero sus validez predictiva siguen siendo controvertidas. Objetivo: Investigar la prediccíon de las herramientas Short Physical Performance Battery (SPPB) y Quick Screen Clinical Fall Risk Assessment (QuickScreen) para identificar el riesgo de caídas en ancianos comunitarios. Método: Estudio metodológico prospectivo con 81 ancianos ( $\geq 60$ años), evaluados en la línea de base por medio de la SPPB y de la QuickScreen y monitoreados después de 1 año para identificación de ocurrencia de caídas. Se calculó la sensibilidad, la especificidad, el valor predictivo positivo (VPP), el valor predictivo negativo (VPN) y el área debajo de la curva ROC (AUC). Resultados: $28,4 \%$ de los ancianos reportaron caídas. QuickScreen presentó una sensibilidad de 52,2\%, especificidad de 74,1\%, VPP de 44,4\%, VPN de 79,6\% y AUC de 0,656. El AUC del $S P P B$ no fue significativo $(p=0,087)$. Conclusión: La herramienta QuickScreen presentó una débil precisión para prever caídas y el SPPB se mostró incapaz de identificar a los ancianos comunitarios en riesgo de caer. La herramienta QuickScreen se destacó por su alto potencial de identificar verdaderos negativos.

Palabras clave: Ancianos. Accidentes por caída. Factores de riesgo. Medición de Riesgo.

Sensibilidad y Especificidad. 


\section{Introduction}

A fall is defined as an involuntary and incorrigible displacement from an individual's initial position to a lower level, resulting from the complex interaction of multi-factorial circumstances, which may be intrinsic, extrinsic, behavioral and environmental $[1,2]$. Falls are considered a highly prevalent event among older adults (from $11 \%$ to $42 \%$ ) [3] and a worrying public health issue due to its disabling or fatal consequences, in addition to the high economic cost it represents. Statistical data have shown that from $19 \%$ to $55 \%$ of the falls reported by older people present harmful consequences such as bruises (46\%) and excoriations (30,7\%) - the most frequent lesions -, and fractures (3\% to 19\%), which is the most disabling consequence due to requiring hospitalization [4-7].

Falls may represent a worrying episode; however, it is an accident that can be prevented by identifying the risk of its occurrence and its risk factors in an early stage [8]. Therefore, instruments to assess fall risk are critical to identify older adults under high risk of fall, referring them to intervention programs that aim at modifying the identified risk factors $[8,9]$. Several instruments to evaluate the physical performance and to identify clinical and physicalfunctional risk factors aimed at preventing the risk of fall exist, the Short Physical Performance Battery (SPPB) [10] and Quick Screen Clinical Falls Risk Assessment (QuickScreen) [11] are two of the most used instruments.

QuickScreen was proposed by Tiedmann et al. [11] and validated in Brazil by de Medeiros [12], this tool can be used in primary health care and seeks to track down the risk of fall in the 12 months after evaluation, considering the multi-factorial characteristic of falls [11]. SPPB was proposed by Guralnick [13] to be used in the investigation of older people presenting risk of future disabilities, it was validated for use in the Brazilian population by Nakano [10]. The instrument is a scale that was originally created to evaluate the physical-functional performance of older adults [10]; however, it includes the possibility of tracing risk of fall via the identification of risk factors associated to body balance, mobility and muscle strength in the lower limbs [14].

These two instruments are of fast application, low cost and can be used by any health professional that has been previously trained in the different areas of care to older adult's health $[10,11]$. They have been widely used in clinical practice and in research, being capable to differentiate fallers from non-fallers among older people [11, 14 - 19]. However, data regarding these instruments predictive validity is still scarce and controversial $[11,16,19]$. Given this context, the objective of this study was to investigate the assessment accuracy of SPPB and QuickScreen to identify risk of fall in community-dwelling older adults.

\section{Methods}

Study design

This is a prospective methodological study that seeks to investigate the accuracy of two clinicalfunctional instruments in the identification of risk of falls in community-dwelling older adults. The study was approved by the Research Ethics Committee (Opinion no. 610.844-0). Data collection was planned before the assessment of the risk of falls and the follow-up of fall occurrences.

\section{Participants}

The participants were selected in a monthly event of health promotion based on convenience. Community-dwelling older adults ( $\geq 60$ years) of both sexes were included. They were submitted to evaluation of risk of fall using QuickScreen and SPPB (index tests). Older people whose individual records were incomplete regarding their initial risk evaluation and those that could not be contacted, via telephone, for monitoring the occurrence of falls after a year of the initial risk evaluation were excluded from the study.

\section{Study period and site}

The initial phase of the study (baseline) was conducted at the Fire Department in the Federal District through the initial evaluation with the selected tools (index tests), from March to December 2016. The follow-up of fall occurrences (reference standard) was conducted via telephone calls 12 months (from March to December 2017) after the initial evaluation to investigate the occurrence of falls (standard reference). 
General Procedures

At baseline, clinical data was collected, and the each older adult had their risk of falls identified using the instruments QuickScreen and SPPB. After a year of the initial evaluation, the occurrence of falls or not and their characteristics were identified via telephone calls. The evaluations of risk of falls were conducted and scored at the beginning of the study by previously trained researchers (two physical therapists accompanied by undergraduate students from the physical therapy course). Telephone calls were made after a year of the beginning of the study by a single previously trained researcher (physical therapist). Such researcher was blinded for the results of the risk of fall tracing test.

\section{Descriptive variables}

Socio-demographic and clinical variables used to describe the sample were: sex, age, schooling, regular practice of physical exercise $(\geq 150$ minutes of weekly practice of moderate physical exercise) [20] and nutritional condition. The characterization of nutritional condition using the body mass index (BMI) was classified as thinness (BMI $<22 \mathrm{Kg} / \mathrm{m}^{2}$ ), eutrophic $\left(\mathrm{BMI}=22-27 \mathrm{Kg} / \mathrm{m}^{2}\right)$ or overweightness $\left(\mathrm{BMI}>27 \mathrm{Kg} / \mathrm{m}^{2}\right)[21]$.

Main variable and study instruments

Risk of falls investigated using the QuickScreen and SPPB tools instruments was characterized as the main variable of the study.

\section{Quick Screen Clinical Falls Risk Assessment (QuickScreen)}

QuickScreen traces the risk of falls through the identification of eight risk factors: history of falls, polypharmacy, use of psychoactive medicine, deficit in visual acuity, peripheral sensitization, static and dynamic balance and weakness of the lower limbs [11].

Data on the history of falls was self-reported by the participants and when one or more falls were reported, it was considered as a risk factor [11].

Polypharmacy was characterized as the use of four or more medicines a day, excluding vitamins and minerals. The use of psychoactive medication was considered another risk factor [11].
Visual acuity in its original composition in the evaluation was conducted through sensitivity to contrast, perception of depth and visual field [11]; however, this study used the Snellen chart $[12,22]$. In that chart, letter " $E$ " is positioned in four different ways over 12 parallel lines, the individual being evaluated sat five meters away from the chart and was asked to indicate the position of the open side of letter " $E$ " in each line. The inability to read all letters up to line five was considered a risk factor [21].

Deficit in peripheral sensitization was identified through the tactile sensitivity test applied at the ankle, more specifically in the lateral malleolus of the dominant lower limb using the 4 gram monofilament Semmes-Weinstein test. The inability to notice two out of three stimuli applied to that region when the patients had their eyes closed and were barefoot was considered a risk factor [11].

Static balance deficit was identified through the near tandem stand test. The participants were asked to position their feet one in front of the other with a $2.5 \mathrm{~cm}$ distance between the back of the heel of the front foot and the hallux of the back foot and a $2.5 \mathrm{~cm}$ distance between the medial region of both feet. The inability to remain in this position for 10 seconds with eyes closed was considered a risk factor for falls [11].

Dynamic balance deficit was identified using the alternate step test. In this test the individual must position the foot plant on an $18 \mathrm{~cm}$ high and $40 \mathrm{~cm}$ deep step and perform eight repetitions alternating the foot on the step (right and left). The time taken to complete the repetitions was clocked and a time of execution longer than 10 seconds was considered a risk factor [11].

Lower limb muscle weakness was identified using the sit-to-stand test. The participant had to perform five fast repetitions of sitting and standing with their arms folded over their chest, in a $43 \mathrm{~cm}$ standard height chair. The test considered the shortest time to accomplish the task in seconds, counted from the moment the individuals stood and finishing when they sat in the chair at the end of the fifth repetition. The time was clocked and when taking over 12 seconds it was considered a risk factor [11].

After evaluating the eight items, the risk factors identified were added for a maximum score of eight points, meaning that the more risk factors were found, the greater the possibility of future falls. A cut-off of four or more factors was considered as indicative of risk of falls [11]. 
Short Physical Performance Battery (SPPB)

SPPB evaluates sequentially static balance, walking speed and lower limb muscle strength, scoring from zero (worst performance) to four (best performance) for each test [10].

The static balance test was conducted considering three orthostatic positions: side-by-side (one foot beside the other), semi-tandem (one foot partially in front of the other) and tandem (one foot in front of the other), respectively. The participant had to remain in each position for 10 seconds. The inability to accomplish the tasks in the estimated time was scored zero; the side-by-side position and the semitandem accomplished within the estimated time got 1 point each. When the tandem position was kept from 3 to 9.99 seconds, it was scored 1 , and when 10 seconds were accomplished, it was scored 2 points [10].

In the walking speed test, the participant should cover a three-meter distance in usual walking speed. The score was determined according to the time of execution, resulting in 0 for the task not being accomplished; 1 for a time longer than 6.52 seconds; 2 for accomplishment between 4.66 and 6.52 seconds; 3 when the task was accomplished between 3.62 and 4.65 seconds and 4 for a time shorter than 3.62 seconds [10].

For the five repetitions in the sit-to-stand test, when the patients could not accomplish it, the score was 0 . When five consecutive repetitions were accomplished and the time needed was over 16.70 seconds, the score was 1 ; when the time was between 13.70 and 16.69 seconds, the score was 2 ; when between 11.20 and 13.69 seconds, the score was 3 , and when the repetitions were accomplished in less than 11.19 seconds, the maximum score of 4 points was given [10].

SPPB can result in a maximum score of 12 points, obtained from the sum of the points achieved in each test; therefore, the higher the score is, the better the performance of the individual under evaluation. Scores between 0 and 3 characterize inability or bad performance; from 4 to 6 , low performance; from 7 to 9 , moderate performance, and from 10 to 12 , good performance [10]. In this study, low or bad performance were considered indicative of risk of falls [14].

\section{Occurrence of incident falls - reference standard}

The occurrence of at least one fall over a year after the initial risk evaluation was considered as a reference standard to investigate the accuracy of the risk of falls tracing instruments [4]. According to this data, the participants were classified as non-fallers (no falls) or fallers (one or more falls) [5].

This step of the research was performed via telephone calls. Participants answered a questionnaire devised by the researchers that included questions about the occurrence and frequency of falls in the period of a year as of the initial evaluation date. When falls were reported in this period, the interviewees were asked about the place where they occurred, the circumstances (cause) and the consequences (injury). When an injury was reported, the participants were further asked about the place of the injury and the intervention needed (how the lesion was treated) [7]

\section{Data analysis and statistical methods}

Data was analyzed descriptively using measures of central tendency (mean and median) and variability (standard deviation and interquartile 25-75) for the continuous variables and frequency measurements and percentage for the categorical variables. Data distribution was analyzed using the KolmogorovSmirnov test.

The occurrence of falls over the follow-up year was calculated using the number of cases of new falls (new cases) recorded during the follow-up year and the total number of individuals at the beginning of the study (Number os cases of incident fall/Total of older adults studied baseline). The differences between the study sub-groups defined according to the incident falls in the sample (non-fallers versus fallers) regarding the QuickScreen and SPPB scores were analyzed using the Mann Whitney-U test and the difference of risk distribution using the Chi-square $\left(\mathrm{X}^{2}\right)$ test. The number of fallers and non-fallers (based on incident falls during the 12 months of the study) with and without risk of fall at baseline (considering the cut-off established in the literature) was obtained for each of the following instruments: (i) QuickScreen; (ii) SPPB.

To analyze the accuracy of the studied instruments some calculations were carried out such as sensitivity (S), specificity (E), positive predictive value (PPV), negative predictive value (NPV), considering false-positive, false-negative, true-negative and true-positive cases. Sensitivity was defined as the percentage of non-fallers accurately identified and specificity was defined as the percentage of non-fallers accurately identified $[23,24]$. PPV was defined as the percentage of positive tests that accurately identified 
future fallers and NPV was defined as the percentage of negative tests that accurately identified non-fallers. Sensitivity and specificity values were considered suitable when over $50 \%$, in which values from $51 \%$ to $69 \%$ characterized weak/limited accuracy and values over $70 \%$ represented good accuracy.

The area below the ROC curve (AUC) with a 95\% confidence interval was calculated to verify the ability of the instruments applied at baseline to discriminate future fallers from non-fallers. AUC values between 0.51 and 0.69 represented weak discriminatory ability and AUC values equal or over 0.70 determined a satisfactory discriminatory ability. For each instrument whose ROC curves presented statistically significant AUC, alternative cut-off points were determined that better discriminated "faller older adults" from "nonfaller older adults", based on the relative balance between sensitivity and specificity.

\section{Results}

From the 124 eligible older adults, seven were excluded for having missing data in their records of risk of falls with the instruments QuickScreen and/ or SPPB. Therefore, 117 phone calls were made to the participants to follow the occurrence of falls over the 12 months after the risk evaluation at baseline, however, 36 participants were not found. Thus, 81 older adults were included in the final analysis of this study, as shown in Figure 1.

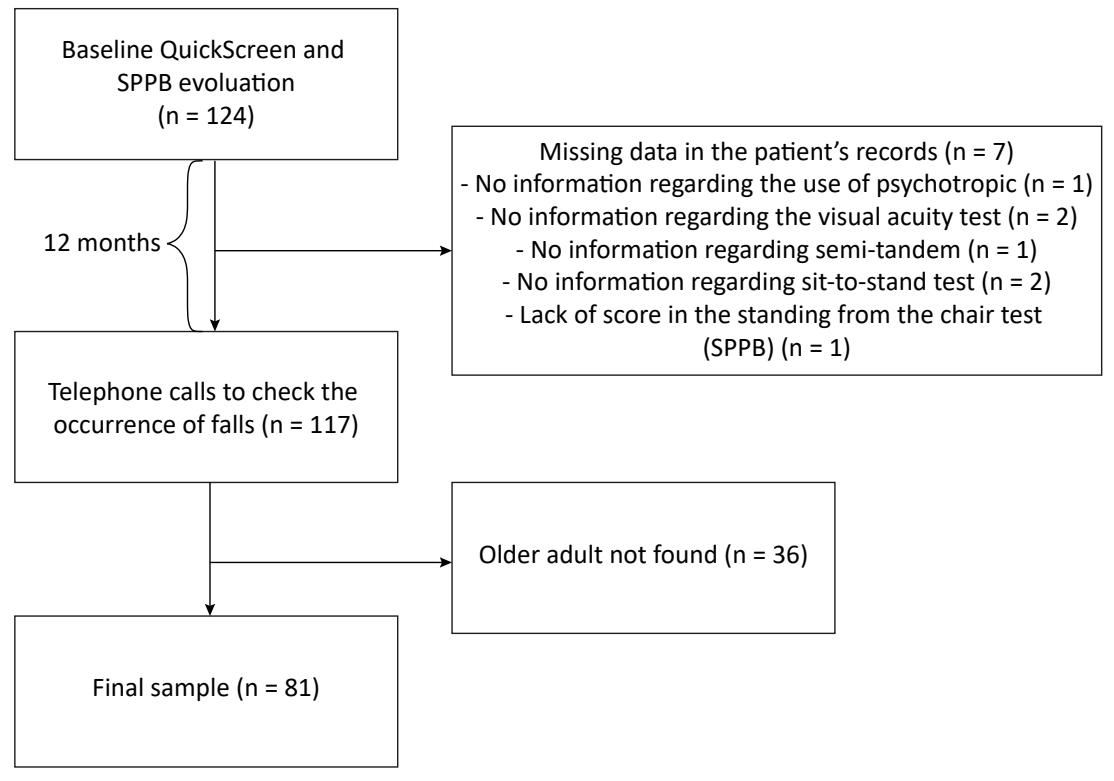

Figure 1-Sample and research procedure flowchart.

Sample characterization and the risk of falls identified by SPPB and QuickScreen are shown in Table 1. Most of the participants were female, eutrophic or overweight and less than half of them did regular physical exercises. During the initial evaluation, QuickSreen pointed out that $33.3 \%$ of the older adults presented risk of future falls. The most frequent risk factors were muscle strength and dynamic balance deficit, polypharmacy and the previous occurrence of falls. SPPB indicated that $14.8 \%$ presented risk of future falls at baseline, with a total median score characteristic of good physical performance. No adverse effects were observed as result of the tests conducted to identify the risk of falls.
Table 1 - Characterization of the sample and risk of falls identified by QuickScreen and SPPB at baseline $(n=81)$

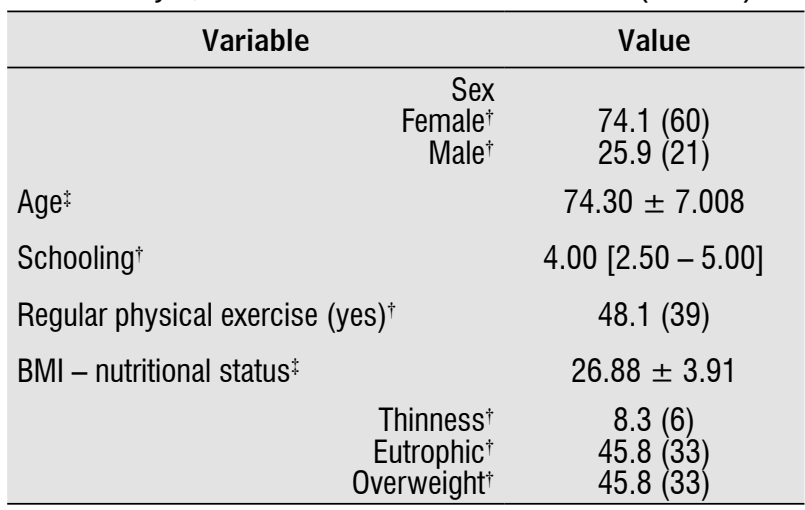

(To be continued) 
(Conclusion)

\begin{tabular}{|c|c|}
\hline Variable & Value \\
\hline $\begin{array}{r}\text { QuickScreen (presence of risk factors) } \\
\text { History of falls } \\
\text { Poypharmacy }\end{array}$ & $\begin{array}{l}40.7(33) \\
44.4(36) \\
\end{array}$ \\
\hline $\begin{array}{r}\text { Use of psychotropic medication } \\
\text { Visual deficit } \\
\text { Sensitivity deficit' } \\
\text { Static balance deficit } \\
\text { Dynamic balance deficit广 } \\
\text { Muscle strength deficit' } \\
\text { Total of risk factors } \\
\text { Risk of falls (yes) }\end{array}$ & $\begin{array}{c}23.5(19) \\
14.8(12) \\
9.9(8) \\
19.8(16) \\
48.1(39) \\
64.2(52) \\
3.00[2.00-4.00] \\
33.3(27)\end{array}$ \\
\hline $\begin{array}{r}\text { Side-by-side feet } \\
\text { Tandem position } \\
\text { Semi-tandem position }^{\ddagger} \\
\text { Walking speed } \\
\text { Sit-to-stand } \\
\text { Total score } \\
\text { Sef }^{\ddagger} \\
\text { Risk of falls (yes) }\end{array}$ & $\begin{array}{c}1 \\
2[1.50-2.00] \\
1[1.00-1.00] \\
4[3.00-4.00] \\
3[2.00-4.00] \\
10[9.00-11.50] \\
14.8(12)\end{array}$ \\
\hline
\end{tabular}

Note: $\mathrm{BMI}=$ Body Mass Index. Percentage values (frequency); tmean \pm standard deviation; ‘median [percentile 25 - percentile 75 ].

The follow-up of occurrence of falls during a year after the initial risk evaluation registered that $28.4 \%$ of the participants reported falls. The most frequent circumstances were slipping and tripping, and the most frequent consequences were swelling and pain, mainly in the lower and upper limbs. Most of the falls required only home care (Table 2 ).

Table 2 - Occurrence of falls follow-up and adverse outcomes

\begin{tabular}{|c|c|}
\hline Variable & Value \\
\hline Falls (yes) ${ }^{\dagger}$ & $28.4(23)$ \\
\hline Falls (number) ${ }^{\ddagger}$ & $1[1-1]$ \\
\hline \multicolumn{2}{|l|}{ Place of falls } \\
\hline $\begin{array}{r}\text { At home }^{\dagger} \\
\text { Out of home } \\
\text { At home and out of home }\end{array}$ & $\begin{array}{c}43.5(10) \\
43.5(10) \\
13.0(3)\end{array}$ \\
\hline \multicolumn{2}{|l|}{ Circumstances of falls } \\
\hline $\begin{array}{r}\text { Slipping }^{\dagger} \\
\text { Tripping } \\
\text { Dizziness }^{\dagger} \\
\text { False stepping } \\
\text { Unbalance }^{\dagger} \\
\text { Unspecified }^{\dagger} \\
\end{array}$ & $\begin{array}{c}23.8(5) \\
19(4) \\
14.3(3) \\
14.3(3) \\
9.5(2) \\
19.2(4) \\
\end{array}$ \\
\hline \multicolumn{2}{|l|}{ Consequence of falls } \\
\hline $\begin{array}{r}\text { Swelling } \\
\text { Pain } \\
\text { Lacerations }^{\dagger} \\
\text { Excoriations } \\
\text { Bruise }^{\dagger} \\
\text { Fracture }^{\dagger}\end{array}$ & $\begin{array}{l}33.4(7) \\
19.1(4) \\
14.3(3) \\
14.3(3) \\
14.3(3) \\
4.8(1)\end{array}$ \\
\hline
\end{tabular}

(To be continued)
(Conclusion)

\begin{tabular}{|c|c|}
\hline Variable & Value \\
\hline \multicolumn{2}{|l|}{ Place of injury } \\
\hline $\begin{array}{r}\text { Lower limbs } \\
\text { Upper limbs } \\
\text { Head and face } \\
\text { More than one place }^{\dagger}\end{array}$ & $\begin{array}{c}33.3(7) \\
28.6(6) \\
9.5(2) \\
28.6(6)\end{array}$ \\
\hline \multicolumn{2}{|l|}{ After-fall intervention } \\
\hline $\begin{array}{r}\text { Care at home } \\
\text { Care at health units } \\
\text { Care at emergency rooms } \\
\text { Care at drugstores }^{\dagger}\end{array}$ & $\begin{array}{c}76,2(16) \\
9,5(2) \\
9,5(2) \\
4,8(1)\end{array}$ \\
\hline
\end{tabular}

Note: Values in percentage (frequency); median [percentile 25 percentile 75].

The comparison between score and distribution of risk of falls in the studied instruments regarding fallers and non-fallers is described in Table 3. Older adults who reported falls in the follow-up period were observed to present score and frequency of risk of falls in the initial evaluation in QuickScreen that was significantly higher than that of non-fallers. No difference of score or frequency of risk of falls were observed in SPPB between fallers and non-fallers. The analysis of the area under the ROC curve indicated the weak accuracy of QuickScreen to predict future falls, with $52.2 \%$ sensitivity and $74.1 \%$ specificity and revealed that SPPB was not able to predict falls (Table 4).

Table 3 - Comparison of risk of falls in QuickScreen and SPPB between fallers and non-fallers

\begin{tabular}{lccc}
\hline & $\begin{array}{c}\text { Non-fallers } \\
(\mathbf{n}=\mathbf{5 8})\end{array}$ & $\begin{array}{c}\text { Fallers } \\
(\mathbf{n}=\mathbf{2 3})\end{array}$ & p-value \\
\hline QuickScreen (score) $^{\ddagger}$ & $2[1-4]$ & $4[2-5]$ & 0.027 \\
QuickScreen (risk) $^{\dagger}$ & $25.9(15)$ & $52.2(12)$ & 0.036 \\
SPPB (score) $)^{\ddagger}$ & $10[8-11]$ & $9[6-10]$ & 0.083 \\
SPPB (risk) & $10.3(6)$ & $26.1(6)$ & 0.090 \\
\hline
\end{tabular}

Note: VValues in percentage (frequency) compared using the Chisquare Test. 'Median [percentile 25 - percentile 75] compared using the Mann Whitney-U test.

Table 4 - Predictive ability of the instruments

\begin{tabular}{lcc}
\hline & QuickScreen & SPPB \\
\hline Cut-off point & 4 risk factors & 7 points \\
Sensitivity & 52.2 & 26.1 \\
Specificity & 74.1 & 89.7 \\
PPV & 44.4 & 50.0 \\
& & (To be continued)
\end{tabular}


(Conclusion)

\begin{tabular}{lcc}
\hline & QuickScreen & SPPB \\
\hline NPV & 79.6 & 75.4 \\
AUC [C|95\%] & $0.656[0.520-0.791]$ & $0.377[0.238-0.517]$ \\
p-value & 0.029 & 0.087 \\
\hline
\end{tabular}

Note: PPV = Positive Predictive Value. NPV $=$ Negative Predictive Value. $\mathrm{AUC}=$ Area under the $\mathrm{ROC}$ curve. $\mathrm{Cl}=$ Confidence Interval.

\section{Discussion}

This study sought to investigate the accuracy of the QuickScreen and SPPB instruments in predicting falls of community-dwelling older adults during the one-year follow-up period. In this period, the frequency of falls found was $28.4 \%$ among the participants. These falls occurred inside and outside of their homes and resulted mainly from slipping and tripping. Most falls provoked swelling and pain in distal regions of the body, demanding some care mainly at the older adult's own home. QuickScreen showed weak predictive ability for these falls and SPPB was shown to be ineffective to evaluate the older adults' risk of falls.

The occurrence of falls recorded in systematically reviewed studies ranged from 11 and $42 \%$ in different regions of the world [3]. In Brazil, Siqueira et al. [6] identified that $27.6 \%$ (IC 95\%: 26.5 - 28.7) of the population interviewed in their study reported falls at some time in the year before the development of the research, which corroborates the findings of this study. Regarding circumstances, slipping and tripping $(22.4 \%-34.6 \%)$ were the most cited as causes of falls, which also corroborates with our results [3]. Furthermore, other studies have presented different consequences of falls among older people $[4,5,7]$, revealing that most of the fallers were looked after in their own homes, as the ones in this study. Regarding the consequences of falls, Sai et al. [5] identified bruises (46\%), excoriations $(30.7 \%)$ and lacerations $(15.3 \%)$ as the most reported injuries among the faller older adults. Regarding fractures, the $4.8 \%$ incidence observed in this study is similar to the occurrence rate reported in the literature, which ranges from $3.4 \%$ to $19 \%[4,7]$.

Muscle weakness, dynamic unbalance and polypharmacy were the most frequent risk factors identified by QuickScreen, similar to the results found by Tiedmann et al. [11] and Garcia et al. [17]. Faller older adults were also observed to present more risk factors in QuickScreen than non-fallers, in accordance with the study conducted by Garcia et al. [17], which identified these differences between nonfaller, faller and recurrent faller older adults, revealing that the multi-dimensional risk evaluation was able to identify falls (OR $=1.347$ [ $95 \%$ IC $1.038-1.748]$ ]) and recurrent falls (OR $=1.378$ [95\% IC 1.014 - 1.873]) in a population of women with low bone mineral density.

This study also revealed that QuickScreen was able to accurately identify the absence of risk of falls in $74.1 \%$ of the older adults who did not fall and $52.2 \%$ presence of risk of the older people who reported having fallen during the one-year follow-up period, although with weak accuracy (AUC $=0.656$ ). Tiedmann et al. [11] evaluated the sensitivity and specificity of each test of this instrument and observed that isolated tests presented better abilities to accurately identify non-faller older adults, with specificity values ranging from 50 to $88 \%$. Those authors identified satisfactory accuracy (AUC $=0.71$ ) of QuickScreen when predicting multiple falls among older adults for one year [11]. Despite finding low specificity value $(33.68 \%)$ and positive predictive value (PPV $=15.86 \%)$, Garcia et al. [16] observed satisfactory sensitivity values $(73.50 \%)$ and negative predictive value (NPV $=88.89 \%$ ) when researching the prediction of multiple falls in a six-months period employing an alternative cut-off point (two or more risk factors).

This study did not find significant difference in the SPPB total score between fallers and non-fallers, thus showing that SPPB was unable to predict the falls that occurred in the follow-up period. However, Kim et al. [25] pointed out important differences in total score $(6.40 \pm 0.93$ vs $10.07 \pm 3.04 ; p=0.000)$ and in the sub-categories of balance evaluation (2.04 \pm 0.34 vs $3.5 \pm 0.76$; $p=0.000)$, walking speed $(2.29 \pm 0.50$ vs $3.32 \pm 2.57 ; \mathrm{p}=0.04)$ and in the sitto-stand test ( $2.08 \pm 0.62$ vs $3.24 \pm 0.88 ; p=0.000$ ) among faller and non-faller older people. They also found a significant correlation between the SPPB score and the fall background (OR $=0.170$ [95\% IC $0.103-0.281]$ ).

Although fallers and non-fallers presented different scores in SPPB and this instrument is considered predictive of older adults' disability, hospitalization and mortality [13], its ability to predict falls, recurrent falls and falls with injury remains controversial [19]. Ward et al. [19] showed that SPPB was unable to predict falls with injury, 
despite having observed that groups of older people with lower performance in the sit-to-stand test and in the walking speed test presented more risk factors for falls than older adults with better performance. Gradkaree et al. [15] observed that, despite the prediction models regarding performance in SPPB associated to self-reported socio-demographic variables (age, gender, self-reported balance deficit and previous falls) being capable of predicting recurrent falls (AUC $=0.79$ [95\% IC 0,76-0.81]), the inclusion of SPPB in the triage protocol did not make the protocol significantly more accurate than the use of simplified protocols that investigated only self-reported risk factors (AUC $=0.77$ [95\% IC 0.74 0.79]). However, Veronese et al. [18] demonstrated that older adults who presented moderate or bad performance (scores from 0 to 6) in SPPB presented greater probability of recurrent falls than those who scored 10-12 (OR $=3.46$, 95\% IC $2.04-5.88$ for women and OR = 3.82 95\% IC 1.77 - 8.52 for men).

Considering these results, we find relevant to discuss the distinct areas evaluated by each studied instrument, which possibly also contributed to the different percentage of risk of falls identified at baseline (QuickScreen $=33 \%, S P P B=14 \%$ ). SPPB only includes evaluations related to older adults' physical performance, which represent fundamental aspects for functionality and characterize intrinsic risk factors regarding the occurrence of falls [10, 13]. However, falls are multifactorial events that also include the influence of socio-demographic and environmental factors, which have been shown to be good predictors but are not addressed in the instrument such as age, history of falls, polypharmacy and use of psychoactive medication [15, 26]. Given this context, QuickScreen outstands for addressing other intrinsic and extrinsic risk factors [27], which were shown to be highly prevalent in the sample, such as the dynamic balance deficit, polypharmacy and the history of falls.

The findings of this study reinforce the complexity of predicting fall events. However, they show that by considering the multidimensionality of falls, the QuickScreen instrument stood out for having accurately predicted $79 \%$ of the tests with negative results, i.e., few false negatives. The consequences and costs of mistakenly classifying an older person as free of risk may be higher than when intervention is provided for an older adult with low risk of falls [28]. On the other hand, Freire et al. [29] considered
SPPB as an important instruments to evaluate older adults' physical performance; however, its use to predict falls still demands further investigation before being inserted in clinical practice with this purpose [30]. In this study, the prospective design with a one-year follow-up of falls using telephone calls, the training and blinding of examiners characterized positive points. However, the absence of a prior sample calculation to determine the sample size characterized a limitation, as well as the low percentage of recurrent fallers (6.2\%) in the followup period prevented the analysis of prediction of multiple falls.

\section{Conclusion}

In conclusion, in this study sample, the QuickScreen instrument presented weak accuracy while SPPB was unable to identify risk of falls in community-dweller elderly. Due to the need for identifying older adults who present higher risk of falls in health care aiming at instructions and guidelines for older adults, duly trained health professionals might opt to use the QuickScreen instrument trusting the high percentage of true negatives demonstrated by it. However, further studies in other regions are needed to strengthen and enable the generalization of our findings.

\section{References}

1. World Health Organization (WHO). WHO Global Report on Falls Prevention in Older Age. Geneva: World Health Organization; 2007. 47 p.

2. Ambrose AF, Paul G, Hausdorff JM. Risk factors for falls among older adults: A review of the literature. Maturitas. 2013;75(1):51-61.

3. Oliveira AS de, Trevizan PF, Bestetti MLT, Melo RC. Fatores ambientais e risco de quedas em idosos: revisão sistemática. Rev Bras Geriatr e Gerontol. 2014;17(3):637-45.

4. Cruz DTD, Ribeiro LC, Vieira MDT, Teixeira MTB, Bastos RR, Leite ICG. Prevalence of falls and associated factors in elderly individuals. Rev Saude Publica. 2012;46(1):138-46.

5. Sai AJ, Gallagher JC, Smith LM, Logsdon S. Fall predictors in the community dwelling elderly: A cross sectional and prospective cohort study. J Musculoskelet Neuronal Interact. 2010;10(2):142-50. 
6. Siqueira FV, Facchini LA, Silveira DS, Piccini RX, Tomasi E, Thumé E, et al. Prevalence of falls in elderly in Brazil: a countrywide analysis. Cad Saude Publica. 2011;27(9):1819-26.

7. Swanenburg J, de Bruin ED, Uebelhart D, Mulder T. Falls prediction in elderly people: A 1-year prospective study. Gait Posture. 2010;31(3):317-21.

8. Park S-H. Tools for assessing fall risk in the elderly: a systematic review and meta-analysis. Aging Clin Exp Res. 2018;30(1):1-6.

9. Sherrington C, Michaleff ZA, Fairhall N, Paul SS, Tiedemman A, Whitney J, et al. Exercise to prevent falls in older adults: An updated systematic review and meta-analysis. Br J Sports Med. 2017;51(24):1749-57.

10. Nakano MM. Versão brasileira da Short Physical Performance Battery (SPPB): adaptação cultural e estudo da confiabilidade [dissertation]. Campinas: Universidade Estadual de Campinas; 2007.

11. Tiedemann A, Lord SR, Sherrington C. The development and validation of a brief performance-based fall risk assessment tool for use in primary care. J Gerontol A Biol Sci Med Sci. 2010;65A(8):896-903.

12. Medeiros RB. Tradução, adaptação cultural e validação do Quick Screen Clinical Falls Risk Assessment para a aplicação em idosos brasileiros [dissertation]. Campinas: Universidade Estadual de Campinas; 2016.

13. Guralnik JM, Simonsick EM, Ferrucci L, Glynn RJ, Berkman LF, Blazer DG, et al. A Short Physical Performance Battery Assessing Lower Extremity Function : Association With Self-Reported Disability and Prediction of Mortality and Nursing Home Admission. J Gerontol. 1994;49(2):85-94.

14. Gomes GAO, Cintra FA, Diogo MJD, Neri AL, Guariento ME, Sousa MLR. Comparação entre idosos que sofreram quedas segundo desempenho físico e número de ocorrências. Rev Bras Fisioter. 2009;13(5):430-7.
15. Gadkaree SK, Sun DQ, Huang J, Varadhan R, Agrawal Y. Comparison of Simple Versus Performance-Based Fall Prediction Models. Gerontol Geriatr Med. 2015;1:1-10.

16. Garcia PA, Dias JMD, Reis RL, Dias RC. Multifactorial assessment of the risk of falls in low bone density older women. Fisioter Mov. 2016;29(3):439-48.

17. Garcia PA, Dias JMD, Silva SLA, Dias RC. Identification of Clinical and Functional Falls Risk Factors Among Low Bone Density Older Women. Top Geriatr Rehabil. 2016;32(2):134-43.

18. Veronese N, Bolzetta F, Toffanello ED, Zanbon S, Rui M, Perissinotto E, et al. Association Between Short Physical Performance Battery and Falls in Older People: The Progetto Veneto Anziani Study. Rejuvenation Res. 2014;17(3):276-84.

19. Ward RE, Leveille SG, Beauchamp MK, Travison T, Alexander N, Jette AM, et al. Functional performance as a predictor of injurious falls in older adults. J Am Geriatr Soc. 2015;63(2):315-20.

20. Nelson ME, Rejeski WJ, Blair SN, Duncan PW, Judge JO, King AC, et al. Physical Activity and Public Health in Older Adults : Recommendation From the American College of Sports Medicine and the American Heart Association. Circulation. 2007;116(9):1094-105.

21. Lipschitz DA. Screening for nutritional status in the elderly. Prim Care. 1994;21(1):55-67.

22. Luiz LC, Rebelatto JR, Coimbra AMV, Ricci NA. Associação entre déficit visual e aspectos clínicofuncionais em idosos da comunidade. Rev Bras Fisioter. 2009;13(4):1-7.

23. Barry E, Galvin R, Keogh C, Horgan F, Fahey T. Is the Timed Up and Go test a useful predictor of risk of falls in community dwelling older adults: a systematic review and meta- analysis. BMC Geriatr. 2014;14(1):14. 
24. Stel VS, Smit JH, Pluijm SMF, Lips P. Balance and mobility performance as treatable risk factors for recurrentfalling in older persons. J Clin Epidemiol. 2003;56:659-68.

25. KIM JC, Chon J, Kim HS, Lee JH, Yoo SD, Kim DH, et al. The association between fall history and physical performance tests in the community-dwelling elderly: A cross-sectional analysis. Ann Rehabil Med. 2017;41(2):239-47.

26. Ministério da Saúde. Departamento de Atenção Básica. Envelhecimento e Saúde Da Pessoa Idosa. Brasília : Ministério da Saúde, 2006. 192 p.

27. Santos FPV, Borges LL, Menezes RL. Correlação entre três instrumentos de avaliação para risco de quedas em idosos. Fisioter Mov. 2013;26(4):883-94.

28. Wrisley DM, Kumar N. Functional Gait Assessment: Concurrent, Discriminative, and Predictive Validity in Community Dwelling Older Adults. Phys Ther. 2010;90(4):1-13.
29. Freire AN, Guerra RO, Alvarado B, Jack M, Zunzunegui MV. Validity and Reliability of the Short Physical Performance Battery in Two Diverse Older Adult Populations in Quebec and Brazil. J Aging Health. 2012;24(5):863-78.

30. Palumbo P, Palmerini L, Bandinelli S, Chiari L. Fall risk assessment tools for elderly living in the community: can we do better? PLoS One. 2015;10(12):146-247.

Received in 08/29 2018

Recebido em 29/08/2018

Recibido en $29 / 08 / 2018$

Approved in 01/15/2019

Aprovado em 15/01/2019

Aprobado en 15/01/2019 